\title{
Salon
}

\section{Medical humanities for what ails us}

A young internist asks her residents if they would like to read and discuss a poem together instead of pursuing the scheduled talk on renal failure. They choose the poem.

An experienced surgeon listens to the Mahler Second after a particularly difficult case fraught with complications.

A medical student meets regularly for coffee with a friend studying architecture. They begin a dialogue on what makes a good hospital.

If you were to ask these physicians what role the medical humanities played in their working lives, they might answer that they were just doing something they liked.

But if you were to press them to tell you what was really happening, you would see that they were creating a space for creative reflection and for thinking and feeling "outside the [medical] box."

These days doctors are struggling to find meaning in their work in the context of sub-subspecialization, dwindling resources, low job satisfaction and burnout. Near-worship at the altar of evidence-based medicine has somehow diminished appreciation for the doctor's subjective experience of working with patients. Instinct, intuition, imagination cannot be measured and perhaps, for this reason, aren't typically seen as "belonging" in the science of medicine.

The medical humanities offer us a formidable remedy for what ails us. A growing body of research has demonstrated that exposure to literature, the fine arts, theology, history, philosophy and anthropology broadens a doctor's cultural competence and encourages the linking of both cognitive and affective approaches to the physician's task. Ongoing dialogue with colleagues from the arts and sciences both complements and stretches our views of health, disease and healing. Poets, musicians and artists have

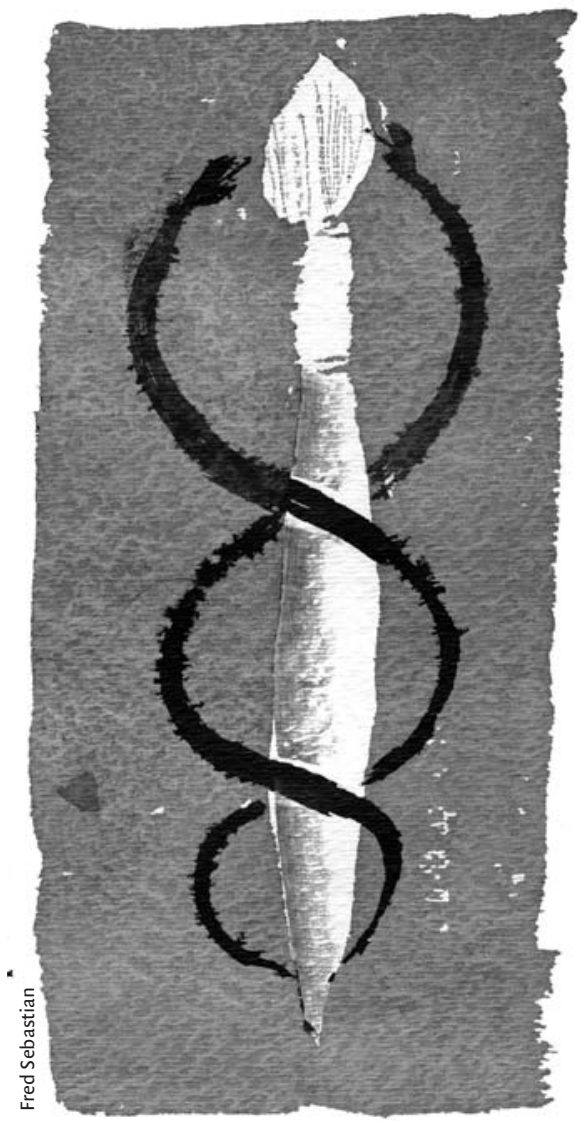

been contemplating suffering for at least as long as we have, and have much to teach us. They also give us permission to rediscover the Art in what we do and to fully imagine what makes that work beautiful.

Until fairly recently, "medical humanists" in Canada have worked in splendid isolation within their communities and even their academic faculties, often because their fascinations and preoccupations seemed "fringy" to their fellow scientists.

What does opera have to do with respirology? Why would a pathologist ask an art gallery to exhibit dissections? Why would a psychiatrist write about the history of wine?

We are starting to see the value in such quirky and unexpected pairings because they place high value on curiosity and on the role of aesthetics in both personal and professional life. An artistic or intellectual passion can provide a new focus for appreciating and recharging our daily work. Creativity should not be "optional" in medicine. It allows us to solve clinical problems in new ways, helps us pull together disparate ideas and sustains us in the face of uncertainty.

Narrative medicine, a form of clinical practice informed by the writing, reading and telling of stories is gaining credibility worldwide as modernists rediscover the value of storytelling in the building of cultures and communities. Formal courses and electives in the medical humanities are now on offer in most Canadian medical schools. Journals like CMAJ, JAMA and ARS MEDICA invite accounts of the doctorpatient encounter in all its singularity so that the thoughts and feelings of both parties can be fully acknowledged.

Like most people, doctors want to find and sustain meaning in what we do. Even more challenging, we work every day with patients who struggle to find new meaning in the face of illness. They expect us to offer guidance on the journey. True healers have always used images, music and poems to help find the way. Little by little, these and many other creative tools are finding their way back into our black bags.

\section{Allan Peterkin MD}

Toronto, Ont.

Allan Peterkin is head of the Program For Narrative and Humanities in Healthcare, the Department of Psychiatry Mount Sinai Hospital and a founding editor of ARS MEDICA: A Journal of Medicine, The Arts and Humanities (www.ars-medica.ca).

Have you got an opinion about this article? Post your views at www.cmaj.ca. Potential Salon contributors are welcome to send a query to salon@cma.ca. 